\title{
Taurine alleviates lipopolysaccharide-induced liver injury by anti-inflammation and antioxidants in rats
}

\author{
YUEYAN LIU ${ }^{1}$, FENG LI $^{1}$, LI ZHANG ${ }^{2}$, JIANFENG WU ${ }^{1}$, YANMEI WANG ${ }^{2}$ and HONG YU ${ }^{1}$ \\ Departments of ${ }^{1}$ Physiology and ${ }^{2}$ Anatomy, School of Clinical Medicine, West Anhui Health Vocational College, \\ Lu'an, Anhui 237005, P.R. China
}

Received May 26, 2016; Accepted April 20, 2017

DOI: $10.3892 / \mathrm{mmr} .2017 .7414$

\begin{abstract}
The aim of the present study was to investigate the protective effect of taurine on lipopolysaccharide (LPS)-induced liver injury and its mechanisms. Male rats were randomly divided into three groups: Normal saline, LPS model and taurine treatment. Experimental animals were treated with saline or taurine (dissolved in saline, $200 \mathrm{mg} / \mathrm{kg} /$ day) via intravenous injection. After $2 \mathrm{~h}$, saline or LPS $(0.5 \mathrm{mg} / \mathrm{kg})$ was administrated via intraperitoneal injection. Markers of liver injury, pro-inflammatory cytokines and superoxide dismutase (SOD) activity were determined in plasma. Liver tissues were removed for morphological analysis and determination by western blot analysis. Taurine significantly reduced the elevation in the levels of LPS-induced aspartate transaminase and alanine transaminase and decreased the concentrations of LPS-induced inflammatory factors including tumor necrosis factor- $\alpha$ and interleukin- 6 . Taurine also increased the activity of SOD in serum and the expression of heme oxygenase-1 protein in liver tissue. Taurine pretreatment also reduced the elevated expression levels of LPS-induced cyclooxygenase-2, nuclear factor $\kappa \mathrm{B}$ and extracellular regulated protein kinase. The results from the present study demonstrated that taurine alleviates LPS-induced liver injury. The beneficial role of taurine may be associated with its reduction of pro-inflammatory response and oxidative stress.
\end{abstract}

\section{Introduction}

Hepatic disorder has become a major disease endangering human health and exhibits a high morbidity and fatality rate (1). As the mechanisms of severe hepatic failure are poorly understood, there remains a lack of effective treatment. An increasing number of studies have suggested that the production of

Correspondence to: Professor Yueyan Liu, Department of Physiology, School of Clinical Medicine, West Anhui Health Vocational College, 9 Gaocheng Road, Lu'an, Anhui 237005, P.R. China

E-mail: liuyueyan_0726@163.com

Key words: taurine, lipopolysaccharide, liver injury inflammatory cytokines serves important roles in various types of liver damage (2,3). Lipopolysaccharide (LPS), a component of Gram-negative bacteria, can activate liver macrophages, which produce inflammatory cytokines including tumor necrosis factor- $\alpha$ (TNF- $\alpha$ ), interleukin (IL)-1 $\beta$ and IL-6 (4-6). In addition, LPS possesses pro-oxidative action via the induction of excessive production of reactive oxygen species (ROS). ROS are the major cause of damage to macromolecules, including protein and DNA, and to the cell membrane, which leads to mitochondrial dysfunction $(7,8)$. A further study demonstrated that ROS are involved in modulation of the inflammatory response (9). Various types of liver damage, including ischemia-reperfusion and liver cancer, are associated with LPS $(10,11)$. Therefore, LPS-induced liver injury is used as an animal model of liver disorder.

Taurine, a sulfur-containing $\beta$-amino acid, is a metabolic product of L-cysteine and is abundant in a number of mammalian tissues. Taurine is not involved in the synthesis of protein; however, considerable evidence has demonstrated that taurine serves a number of vital roles in physiological processes, including regulation of calcium concentration (12), stabilization of the cell membrane (13), regulation of blood pressure and protection of endothelial cells (14). The antioxidant properties of taurine have been confirmed by a number of results, although taurine itself is not able to scavenge ROS. Taurine exerts its antioxidant action by inhibiting the production of ROS, which result from the increasing activities of antioxidases (15). Certain studies have indicated that taurine protects cells against oxidative stress $(16,17)$. Taurine is changed into taurine chloramine $(\mathrm{TauCl})$ in vivo, which inhibits secretion of pro-inflammatory cytokines including IL-6, IL-1 $\beta$, TNF- $\alpha$ and IL-8 $(18,19)$. It is suggested that taurine is a potent anti-inflammatory factor.

The present study examined the beneficial effects of taurine on LPS-induced liver injury in rats. The results suggested that administration of taurine may be beneficial for patients with hepatopathy.

\section{Materials and methods}

Animals and experimental design. A total of 30 healthy male Sprague-Dawley rats (weighing $280 \pm 20 \mathrm{~g}$ ) were obtained from the Animal Center at West Anhui Health Vocational College and housed in a standard facility at $22^{\circ} \mathrm{C}$ and $50-70 \%$ humidity 
with a 12-h light/dark cycle. Experimental rats received a standard pellet diet and water ad libitum. The study was approved by the Ethics Committee of West Anhui Health Vocational College (Lu'an, China). After a week, the animals were randomly divided into three groups ( $n=10$ per group): i) Normal saline group (NS), ii) LPS control group (LPS) and iii) taurine + LPS group (TL). Rats from NS and LPS were treated with sterile saline by intravenous injection and animals from TL were intravenously injected with taurine $(100 \mathrm{mg} / \mathrm{kg}$ body weight, dissolved in sterile saline; Sigma-Aldrich; Merck KGaA, Darmstadt, Germany). After $4 \mathrm{~h}$, rats from LPS and TL groups were intraperitoneally injected with LPS $(10 \mathrm{mg} / \mathrm{kg}$ body weight, dissolved in sterile saline; Sigma-Aldrich; Merck $\mathrm{KGaA}$ ) and NS rats received sterile saline. At $6 \mathrm{~h}$ following administration of LPS, the animals were anesthetized with sodium pentobarbital (50 mg/kg, i.p.; Sigma-Aldrich; Merck $\mathrm{KGaA}$ ) to collect blood samples prior to animal sacrifice. Fasting blood samples were collected by artery catheterization for biochemical analyses and liver tissues were obtained for histological analyses.

Determination of liver function. Fasting blood samples were centrifuged at 3,000 x g to separate the serum. Markers of liver function, serum aspartate transaminase (AST) and alanine transaminase (ALT) were determined using an enzymatic colorimetric method (Diagnostica Stago S.A.S., Paris, France) according to the manufacturer's protocols and analyzed by a semi-automatic analyzer, with the results being expressed as U/1.

Measurement of inflammatory cytokines. Serum levels of TNF- $\alpha$, procalcitonin (PCT) and IL- 6 were detected with rat TNF- $\alpha$ (cat. no. ELS-2855-1), PCT (cat. no. ELS-3485-1) and IL-6 (cat. no. ELS-2866-1) specific ELISA kits (Hefei Bomei Biotechnology Co., Ltd., Hefei, China) according to manufacturer's protocol. The levels of TNF- $\alpha$ and IL- 6 were expressed as ng/l.

Estimation of antioxidant effects. To estimate changes in antioxidant effects, the activity of the antioxidase, superoxide dismutase (SOD) was determined using xanthine oxidase methods, and the content of lipid peroxidation production, malonaldehyde (MDA), was measured using thiobarbituric acid methods, according to the manufacturer's protocol (both from Nanjing Jiancheng Bioengineering Institute, Nanjing, China)

Histological analysis. Liver tissues were harvested and fixed in $4 \%$ phosphate-buffered formalin for pathological analysis. Fixed tissues were dehydrated in ethanol, embedded in paraffin and $5 \mu \mathrm{m}$ sections were cut. After drying overnight, sections were dewaxed, rehydrated and stained with hematoxylin and eosin (H\&E) for histomorphological observation under a light microscope.

Western blot analysis. Liver tissues (0.2 g) were harvested, lysed and homogenized in $2 \mathrm{ml}$ lysis buffer with $10 \mathrm{mM}$ Tris-buffered saline, 1 mM EDTA, 1 mM EGTA, 2 mM PMSF and $1 \%$ Triton X-100 (v/v) for $20 \mathrm{~min}$. Lysates were centrifuged at $13,000 \mathrm{x} \mathrm{g}$ for $15 \mathrm{~min}$ at $4^{\circ} \mathrm{C}$. Protein concentration was measured using a Quick Start ${ }^{\mathrm{TM}}$ Bradford protein assay
(Bio-Rad Laboratories, Inc., Hercules, CA, USA). Denatured proteins in supernatants were separated by $10 \%$ SDS-PAGE and transferred onto nitrocellulose membranes. The membranes were blocked with $5 \%$ non-fat milk in TBS with Tween-20 (10 mM Tris- $\mathrm{HCl}, 150 \mathrm{mM} \mathrm{NaCl}$ and $1 \%$ Tween-20) for $2 \mathrm{~h}$. The membranes were subsequently incubated with primary polyclonal antibodies against $\beta$-actin $(1: 1,000)$, heme oxygenase-1 (HO-1; 1:1,000), cyclooxygenase-2 (COX-2), nuclear factor $(\mathrm{NF})-\kappa \mathrm{B}$, phosphorylated $(\mathrm{p})-\mathrm{NF}-\kappa \mathrm{B}$, extracellular signal-regulated kinase (ERK) and p-ERK1/2 (Bio Basic Inc., Markham, ON, Canada) overnight at $4^{\circ} \mathrm{C}$. Following an extensive wash with TBST, the membranes were incubated with a horseradish peroxidase-conjugated goat anti-rabbit secondary antibody (1:10,000; cat. no. A9169; Sigma-Aldrich; Merck $\mathrm{KGaA}$ ) for $2 \mathrm{~h}$ at room temperature. The membranes were washed three times and visualized with 3,3'-diaminobenzidine (Bio Basic Inc.).

Statistical analysis. All values are expressed as mean \pm standard deviation. The data were analyzed using SPSS version 16.0 (SPSS, Inc., Chicago, IL, USA). Statistical difference was determined by Tukey's test for unpaired data or one-way analysis of variance with least significant difference-t and/or Tamhane's $\mathrm{T}_{2}$ post hoc tests for multiple comparisons. $\mathrm{P}<0.05$ was considered statistically to indicate a statistically significant difference.

\section{Results}

Ameliorative effects of taurine on liver damage. To examine liver function, serum AST and ALT transaminases were determined. The result demonstrated a significant increase in activity of AST and ALT in LPS rats compared with NS rats $(\mathrm{P}<0.01$; Fig. 1). Administration of taurine reduced the increase in activity of AST and ALT (P<0.01; Fig. 1).

Change of antioxidant effects. The activity of serum SOD, an antioxidase, was reduced and the content of serum MDA, a product of lipid peroxidation, was increased in LPS-treated rats compared with NS rats $(\mathrm{P}<0.01$; Fig. 2$)$. Taurine significantly enhanced SOD activity and decreased the concentration of MDA ( $\mathrm{P}<0.01$; Fig. 2).

Effects of taurine on pro-inflammatory cytokines. The levels of TNF- $\alpha$ and IL- 6 in serum were significantly increased in LPS rats $(\mathrm{P}<0.01$; Fig. $3 \mathrm{~A}$ and $\mathrm{B})$ and an increased level of PCT was determined $(\mathrm{P}<0.05$; Fig. $3 \mathrm{C})$. Taurine treatment prior to LPS significantly reduced the levels of TNF- $\alpha$ and IL-6 ( $<<0.01$; Fig. 3A and B) and decreased the concentration of PCT $(\mathrm{P}<0.05$; Fig. $3 \mathrm{C})$.

Effects of taurine on hepatic histopathology. Liver sections stained with H\&E were observed under a light microscope for hepatic morphology. Recruitment of inflammatory cells and release of inflammatory factors in liver are involved in liver injury (20). Exposure to LPS resulted in an increase in the infiltration of inflammatory cells and hepatocyte edema (Fig. 4). Administration of taurine prior to LPS attenuated congestion in liver tissues, abated the number of the infiltration of inflammatory cells and intact lobular structure was observed (Fig. 4). 


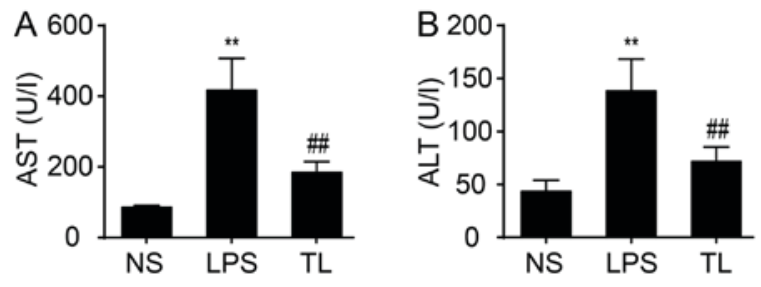

Figure 1. Effects of taurine on the levels of (A) AST and (B) ALT. Data are presented as the mean \pm standard deviation $(n=10)$. ${ }^{* *} \mathrm{P}<0.01$ vs. NS group and ${ }^{\# \#} \mathrm{P}<0.01$ vs. LPS group. AST, aspartate transaminase; ALT, alanine transaminase; NS, normal saline group; LPS, lipopolysaccharide control group; TL, taurine + LPS group.
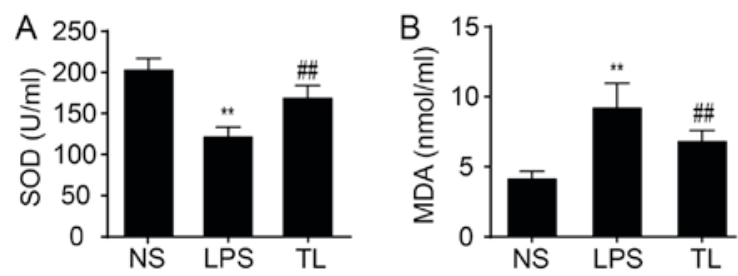

Figure 2. Effects of taurine on the levels of (A)SOD and (B) MDA. Data are presented as the mean \pm standard deviation $(n=10) .{ }^{* *} \mathrm{P}<0.01$ vs. NS group and ${ }^{\# \#} \mathrm{P}<0.01$ vs. LPS group. SOD, superoxide dismutase; MDA, malonaldehyde; NS, normal saline group; LPS, lipopolysaccharide control group; TL, taurine + LPS group.

Effects of taurine on liver ERK1/2, COX-2, HO-1 and NF- $\mathrm{BB}$ protein expression. Antioxidant alterations were examined; taurine pretreatment elevated $\mathrm{HO}-1$ protein expression (Fig. 5A). Furthermore, the protein expression levels of COX-2 (Fig. 5B), NF-кB (Fig. 5C) and p-ERK (Fig. 5D) were investigated to evaluate inflammation signaling. Taurine pretreatment reduced the protein expression of NF- $\mathrm{B}, \mathrm{COX}-2$ and $\mathrm{p}-\mathrm{ERK}$.

\section{Discussion}

It is well-known that activation of macrophages and release of inflammatory cytokines serve important roles in organ damage, including acute and chronic liver injury $(21,22)$. The present study aimed to investigate effects of taurine pretreatment on LPS-induced liver injury. The results demonstrated that taurine pretreatment by intravenous injection reduced the activity of plasma AST and ALT, and decreased the level of serum inflammatory cytokines including TNF- $\alpha$, IL-6 and MDA. Serum SOD activity and HO-1 protein expression in liver was significantly increased in taurine-pretreated rats, while $\mathrm{COX}-2, \mathrm{pNF}-\kappa \mathrm{B}(\mathrm{E})$ and $\mathrm{p}-\mathrm{ERK}$ protein expression levels in liver were reduced. In addition, taurine pretreatment alleviated the infiltration of inflammatory cells in liver tissues and hepatic congestion. The present study suggested that taurine pretreatment protected the liver against LPS-induced injury.

LPS-induced tissue injury results from an increase in the release of cytokines, oxidative stress and impairment of mitochondrial function (23). LPS induces excessive release of pro-inflammatory cytokines including TNF- $\alpha$ and IL-6 and the production of ROS by binding with Toll-like receptor 4 on the surface of Küpffer cells $(24,25)$, stimulating the apoptosis of hepatic cells and necrosis (26).
Oxidative stress results from excessive generation of ROS and/or deletion of antioxidants including reduced activities of the antioxidant enzymes, imbalance of glutathione redox status (27) and increased products of lipid peroxidation (28), which damages cells via macromolecules and mitochondrial dysfunction, further harming various tissues including the liver $(7,29)$. Release of ROS is a mechanism of LPS-induced hepatic injury, therefore reduction of ROS signaling relieves such damage (30). Studies have indicated that treatment with antioxidant and anti-inflammatory agents is beneficial in LPS-induced hepatic injury $(31,32)$, and that taurine can reduce oxidative stress $(33,34)$ and relieve tissue injuries by its antioxidative properties $(35,36)$. The results of the present study indicated that administration of LPS resulted increased ALT and AST activities in serum, considered as markers of liver injury. Taurine pretreatment reduced the increases of ALT and AST, and decreased the concentration of MDA, a marker of lipid peroxidation; it also elevated the activity of SOD and the protein expression of antioxidant enzyme HO-1.

Inflammatory response serves an important role in various liver disorders. LPS initiates inflammation by recruiting neutrophils to the liver and subsequently stimulating the expression of inflammatory factors, including TNF- $\alpha$, which provoke the release of ROS (37). The results of the present study demonstrated that LPS elevated the levels of TNF- $\alpha$ and IL- 6 in serum and expression of COX -2 and $N F-\kappa B$ protein. Taurine pretreatment reduced the expression of pro-inflammatory proteins including $\mathrm{COX}-2$ and $\mathrm{NF}-\kappa \mathrm{B}$.

It is reported that taurine is converted into taurine chloramine in vivo and that this reduces the inflammatory response (38). Taurine increases its antioxidative effects by increasing the expression of HO-1 protein (39), which is reported to inhibit expression of COX-2 (40). COX-2 induces the production of prostaglandin, which is involved in inflammation and pain and results in cellular injury $(41,42)$. HO-1, an inducible rate-limiting enzyme, catalyzes heme into equimolar amounts of carbon monoxide (CO), biliverdin and free iron. Induction of HO-1 may protect against oxidative stress-related cell and tissue injury $(40,43)$. Biliverdin has been confirmed to be a potent antioxidant (44). CO, a catalytic product of $\mathrm{HO}-1$, exerts antioxidative, anti-inflammatory and anti-apoptotic effects (45). Increasing evidence has confirmed that the $\mathrm{HO} / \mathrm{CO}$ signaling exerts a vital role in regulation of anti-inflammation and cytoprotection (46-48).

$\mathrm{NF}-\kappa \mathrm{B}$ is involved in LPS signaling. Activation of NF- $\kappa \mathrm{B}$ by LPS upregulates the expression of COX-2 (49). It is reported that the anti-inflammatory effect of $\mathrm{CO}$ is associated with its regulation on transcription factors including $\mathrm{NF}-\kappa \mathrm{B}(50,51)$. A previous study demonstrated that $\mathrm{CO}$ alleviates LPS-induced inflammation by suppression of $N F-\kappa B(48)$. The results suggested that taurine inhibited $\mathrm{NF}-\kappa \mathrm{B} / \mathrm{COX}-2$ signaling via induction of HO-1. In addition, the mitogen-activated protein kinase (MAPK)/ERK pathway is implicated in LPS-induced inflammation (52) and is an upstream mediator of $\mathrm{NF}-\kappa \mathrm{B}$ nuclear translocation $(53,54)$. Another study demonstrated that reduced MAPK/ERK1/2 signaling downregulates $\mathrm{NF}-\kappa \mathrm{B}$ in LPS-activated hepatocytes (54). Recent studies have indicated that increased levels of phosphorylated ERK and c-Jun N-terminal kinases promote COX-2 protein expression $(55,56)$. 

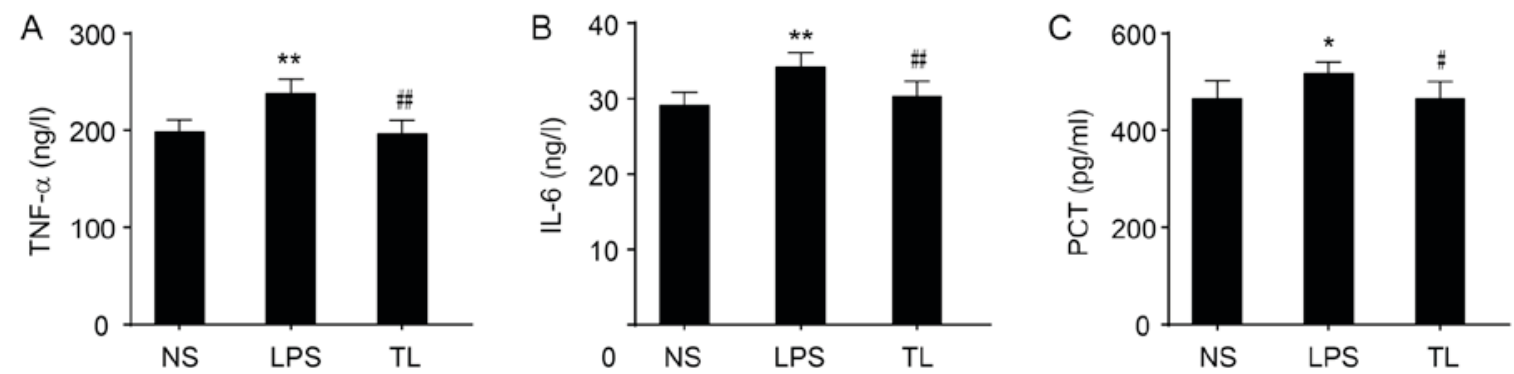

Figure 3. Effects of taurine on the levels of (A) IL-6, (B) TNF- $\alpha$ and (C) PCT. Data are presented as the mean \pm standard deviation ( $\mathrm{n}=10$ ). "P<0.05 vs. NS group, ${ }^{* *} \mathrm{P}<0.01$ vs. NS group, ${ }^{\#} \mathrm{P}<0.05$ vs. LPS group and ${ }^{\# \#} \mathrm{P}<0.01$ vs. LPS group. IL-6, interleukin 6 ; TNF- $\alpha$, tumor necrosis factor- $\alpha$; PCT, procalcitonin; NS, normal saline group; LPS, lipopolysaccharide control group; TL, taurine + LPS group.

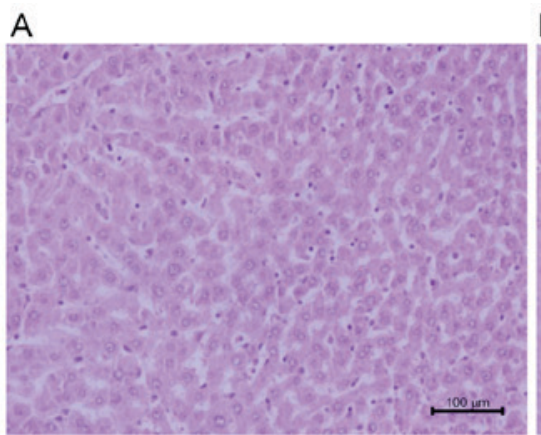

B

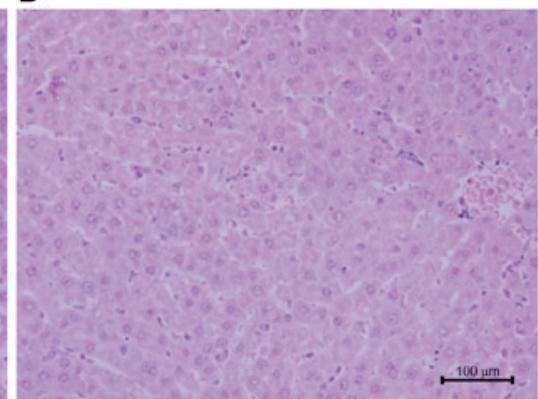

C

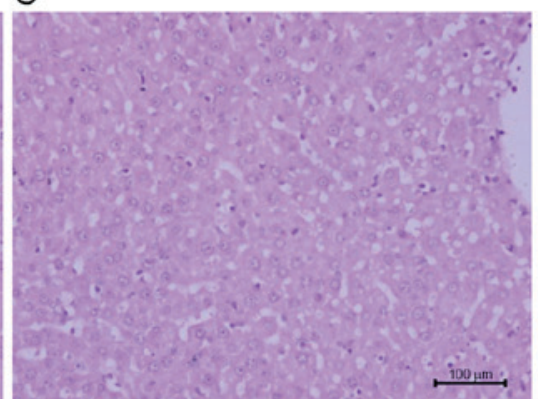

Figure 4. Photomicrographs of hematoxylin and eosin staining in the liver tissue of each group. (A) NS group, (B) LPS group and (C) TL group. Scale bar, $100 \mu \mathrm{m}$. NS, normal saline group; LPS, lipopolysaccharide control group; TL, taurine + LPS group.

A

HO-1
$\beta$-actin

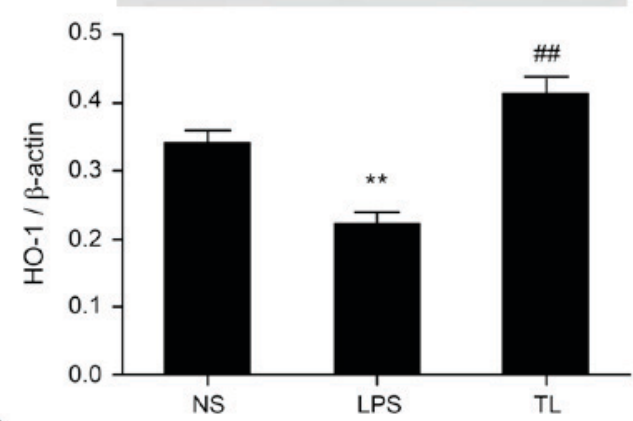

C
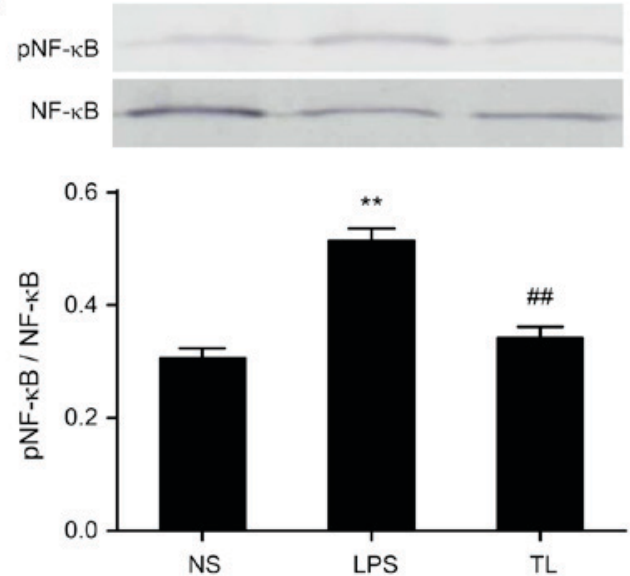

B

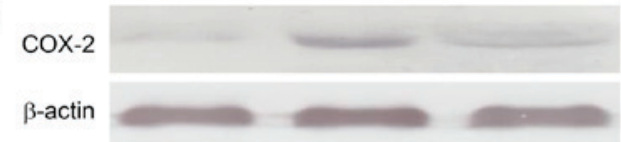

D
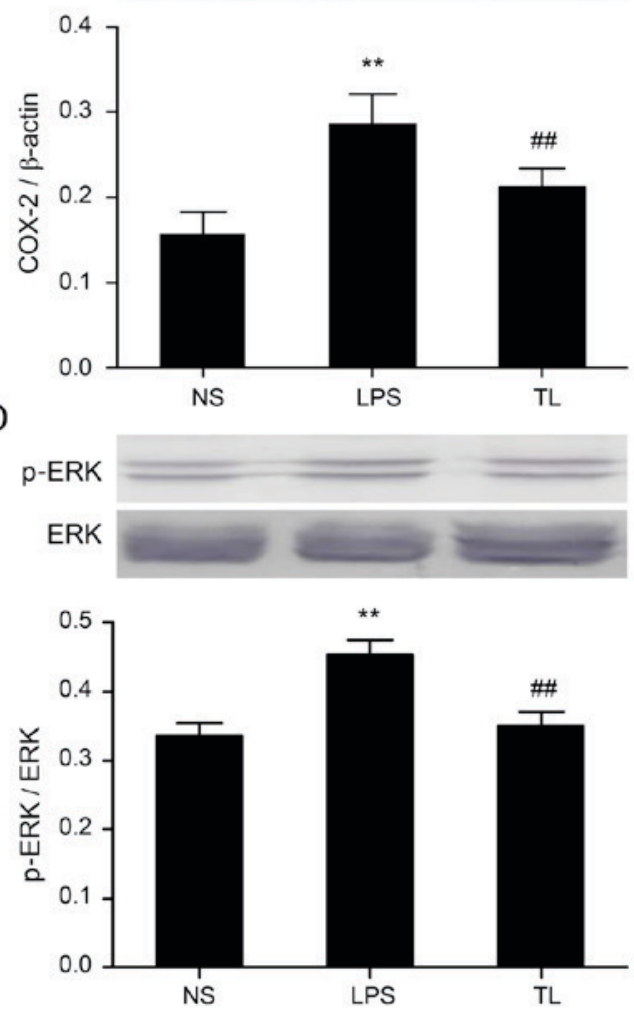

Figure 5. Effects of taurine on the expression levels of HO-1, COX-2, pNF- $\kappa$ B and p-ERK protein. Representative western blot images and quantification of (A) HO-1, (B) COX-2, (C) pNF- $\kappa$ B and (D) p-ERK. Data are presented as the mean \pm standard deviation. ${ }^{* *} \mathrm{P}<0.01 \mathrm{vs}$. NS group and ${ }^{\# \#} \mathrm{P}<0.01 \mathrm{vs}$. TL group; $\mathrm{n}=6$ per group. $\mathrm{HO}-1$, heme oxygenase-1; COX-2, cyclooxygenase-2; NF- $\kappa \mathrm{B}$, nuclear factor- $\kappa \mathrm{B}$; ERK, extracellular signal-regulated kinase; $\mathrm{p}-$, phosphorylated. 
In conclusion, the results of the present study indicated that taurine pretreatment protected the liver against LPS-induced injury by increasing its antioxidation and anti-inflammation ability, which were associated with the increased expression of $\mathrm{HO}-1$ protein and reduced expression levels of $\mathrm{NF}-\kappa \mathrm{B}, \mathrm{COX}-2$ and $\mathrm{p}$-ERK proteins. The findings suggested that taurine reduced $\mathrm{NF}-\kappa \mathrm{B} / \mathrm{COX}-2$ signaling by activation of $\mathrm{HO}-1 / \mathrm{CO}$.

\section{Acknowledgements}

The present study was supported by the Outstanding Young Talent Fund Key Project of Anhui Province (grant no. 2013SQRL146ZD).

\section{References}

1. Mizuhara H, O'Neill E, Seki N, Ogawa T, Kusunoki C, Otsuka K, Satoh S, Niwa M, Senoh H and Fujiwara H: T cell activation-associated hepatic injury: Mediation by tumor necrosis factors and protection by interleukin 6. J Exp Med 179: 1529-1537, 1994.

2. Gasparini $C$ and Feldmann M: NF- $\kappa B$ as a target for modulating inflammatory responses. Curr Pharm Des 18: 5735-5745, 2012.

3. Josephs MD, Bahjat FR, Fukuzuka K, Ksontini R, Solorzano CC, Edwards CK III, Tannahill CL, MacKay SL, Copeland EM III and Moldawer LL: Lipopolysaccharide and D-galactosamine-induced hepatic injury is mediated by TNF-alpha and not by Fas ligand. Am J Physiol Regul Integr Comp Physiol 278: R1196-R1201, 2000

4. Enomoto N, Ikejima K, Bradford BU, Rivera CA, Kono H, Goto M, Yamashina S, Schemmer P, Kitamura T, Oide H, et al Role of Kupffer cells and gut-derived endotoxins in alcoholic liver injury. J Gastroenterol Hepatol 15 (Suppl): D20-D25, 2000

5. Uesugi T, Froh M, Arteel GE, Bradford BU, Wheeler MD, Gäbele E, Isayama F and Thurman RG: Role of lipopolysaccharide-binding protein in early alcohol-induced liver injury in mice. J Immunol 168: 2963-2969, 2002.

6. Enomoto N, Schemmer P, Ikejima K, Takei Y, Sato N, Brenner DA and Thurman RG: Long-term alcohol exposure changes sensitivity of rat Kupffer cells to lipopolysaccharide. Alcohol Clin Exp Res 25: 1360-1367, 2001.

7. Cadenas S and Cadenas AM: Fighting the stranger-antioxidant protection against endotoxin toxicity. Toxicology 180: 45-63, 2002.

8. Mallis RJ, Buss JE and Thomas JA: Oxidative modification of H-ras: S-thiolation and S-nitrosylation of reactive cysteines Biochem J 355: 145-153, 2001.

9. Zuo Y, Xiang B, Yang J, Sun X, Wang Y, Cang H and Yi J: Oxidative modification of caspase-9 facilitates its activation via disulfide-mediated interaction with Apaf-1. Cell Res 19: 449-457, 2009.

10. Colletti LM and Green M: Lung and liver injury following hepatic ischemia/reperfusion in the rat is increased by exogenous lipopolysaccharide which also increases hepatic TNF production in vivo and in vitro. Shock 16: 312-319, 2001.

11. Yu LX, Yan HX, Liu Q, Yang W, Wu HP, Dong W, Tang L, Lin Y, He YQ, Zou SS, et al: Endotoxin accumulation prevents carcinogen-induced apoptosis and promotes liver tumorigenesis in rodents. Hepatology 52: 1322-1333, 2010.

12. Huxtable RJ: Physiological actions of taurine. Physiol Rev 72: 101-163, 1992.

13. Pasantes-Morales H, Wright CE and Gaull GE: Taurine protection of lymphoblastoid cells from iron-ascorbate induced damage. Biochem Pharmacol 34: 2205-2207, 1985.

14. Maia AR, Batista TM, Victorio JA, Clerici SP, Delbin MA, Carneiro EM and Davel AP: Taurine supplementation reduces blood pressure and prevents endothelial dysfunction and oxidative stress in post-weaning protein-restricted rats. PLoS One 9: e105851, 2014.

15. Sun Jang J, Piao S, Cha YN and Kim C: Taurine chloramine activates Nrf2, increases HO-1 expression and protects cells from death caused by hydrogen peroxide. J Clin Biochem Nutr 45 37-43, 2009.

16. Schaffer SW, Azuma J and Mozaffari M: Role of antioxidant activity of taurine in diabetes. Can J Physiol Pharmacol 87: 91-99, 2009.
17. Erdamar H, Turközkan N, Ekremoğlu M, Kurt Y and Yaman H: The effect of taurine on polymorphonuclear leukocyte functions in endotoxemia. Amino Acids 33: 581-585, 2007.

18. Kontny E, Plebanczyk M, Lisowska B, Olszewska M, Maldyk P and Maslinski W: Comparison of rheumatoid articular adipose and synovial tissue reactivity to proinflammatory stimuli: Contribution to adipocytokine network. Ann Rheum Dis 71: 262-267, 2012.

19. Marcinkiewicz J and Kontny E: Taurine and inflammatory diseases. Amino Acids 46: 7-20, 2014.

20. Ambade A, Catalano D, Lim A and Mandrekar P: Inhibition of heat shock protein (molecular weight $90 \mathrm{kDa}$ ) attenuates proinflammatory cytokines and prevents lipopolysaccharide-induced liver injury in mice. Hepatology 55: 1585-1595, 2012.

21. Rossignol DP and Lynn M: TLR4 antagonists for endotoxemia and beyond. Curr Opin Investig Drugs 6: 496-502, 2005.

22. Nolan JP: The role of intestinal endotoxin in liver injury: A long and evolving history. Hepatology 52: 1829-1835, 2010.

23. Lowes DA, Webster NR, Murphy MP and Galley HF: Antioxidants that protect mitochondria reduce interleukin- 6 and oxidative stress, improve mitochondrial function, and reduce biochemical markers of organ dysfunction in a rat model of acute sepsis. Br J Anaesth 110: 472-480, 2013.

24. Sun S, Zhang H, Xue B, Wu Y, Wang J, Yin Z and Luo L: Protective effect of glutathione against lipopolysaccharide-induced inflammation and mortality in rats. Inflamm Res 55: 504-510, 2006.

25. Ohsaki Y, Shirakawa H, Hiwatashi K, Furukawa Y, Mizutani T and Komai M: Vitamin K suppresses lipopolysaccharide-induced inflammation in the rat. Biosci Biotechnol Biochem 70: 926-932, 2006.

26. Wang Y, Gao LN, Cui YL and Jiang HL: Protective effect of danhong injection on acute hepatic failure induced by lipopolysaccharide and d-galactosamine in mice. Evid Based Complement Alternat Med 2014: 153902, 2014.

27. Davies KJ: Protein damage and degradation by oxygen radicals. I. General aspects. J Biol Chem 262: 9895-9901, 1987.

28. Klein T, Neuhaus K, Reutter F and Nüsing RM: Generation of 8-epi-prostaglandin $\mathrm{F}$ (2alpha) in isolated rat kidney glomeruli by a radical-independent mechanism. Br J Pharmacol 133: 643-650, 2001.

29. Sewerynek E, Melchiorri D, Chen L and Reiter RJ: Melatonin reduces both basal and bacterial lipopolysaccharide-induced lipid peroxidation in vitro. Free Radic Biol Med 19: 903-909, 1995.

30. Hsing CH, Lin MC, Choi PC, Huang WC, Kai JI, Tsai CC, Cheng YL, Hsieh CY, Wang CY, Chang YP, et al: Anesthetic propofol reduces endotoxic inflammation by inhibiting reactive oxygen species-regulated Akt/IKK $\beta / \mathrm{NF}-\mathrm{kB}$ signaling. PLoS One 6: e17598, 2011.

31. Ajuwon OR, Oguntibeju OO and Marnewick JL: Amelioration of lipopolysaccharide-induced liver injury by aqueous rooibos (Aspalathus linearis) extract via inhibition of pro-inflammatory cytokines and oxidative stress. BMC Complement Altern Med 14: 392,2014

32. Takata J, Ito S, Karube Y, Nagata Y and Matsushima Y: Watersoluble prodrug of vitamin $\mathrm{E}$ for parenteral use and its effect on endotoxin-induced liver toxicity. Biol Pharm Bull 20: 204-209, 1997.

33. Oliveira MW, Minotto JB, de Oliveira MR, Zanotto-Filho A, Behr GA, Rocha RF, Moreira JC and Klamt F: Scavenging and antioxidant potential of physiological taurine concentrations against different reactive oxygen/nitrogen species. Pharmacol Rep 62: 185-193, 2010.

34. Jeon SH, Lee MY, Rahman MM, Kim SJ, Kim GB, Park SY, Hong CU, Kim SZ, Kim JS and Kang HS: The antioxidant, taurine reduced lipopolysaccharide (LPS)-induced generation of ROS, and activation of MAPKs and Bax in cultured pneumocytes. Pulm Pharmacol Ther 22: 562-566, 2009.

35. Motawi TK, Abd Elgawad HM and Shahin NN: Modulation of indomethacin-induced gastric injury by spermine and taurine in rats. J Biochem Mol Toxicol 21: 280-288, 2007.

36. Shimizu M, Zhao Z, Ishimoto Y and Satsu H: Dietary taurine attenuates dextran sulfate sodium (DSS)-induced experimental colitis in mice. Adv Exp Med Biol 643: 265-271, 2009.

37. McDonald B, Jenne CN, Zhuo L, Kimata K and Kubes P: Kupffer cells and activation of endothelial TLR4 coordinate neutrophil adhesion within liver sinusoids during endotoxemia. Am J Physiol Gastrointest Liver Physiol 305: G797-G806, 2013.

38. Weiss SJ, Klein R, Slivka A and Wei M: Chlorination of taurine by human neutrophils. Evidence for hypochlorous acid generation. J Clin Invest 70: 598-607, 1982. 
39. Wang GG, Li W, Lu XH, Zhao X and Xu L: Taurine attenuates oxidative stress and alleviates cardiac failure in type I diabetic rats. Croat Med J 54: 171-179, 2013.

40. Shih RH and Yang CM: Induction of heme oxygenase-1 attenuates lipopolysaccharide-induced cyclooxygenase- 2 expression in mouse brain endothelial cells. J Neuroinflammation 7: 86, 2010.

41. Fletcher JR: Eicosanoids. Critical agents in the physiological process and cellular injury. Arch Surg 128: 1192-1196, 1993.

42. Williams JA and Shacter E: Regulation of macrophage cytokine production by prostaglandin E2. Distinct roles of cyclooxygenase-1 and -2. J Biol Chem 272: 25693-25699, 1997.

43. Chen QY, Wang GG, Li W, Jiang YX, Lu XH and Zhou PP: Heme oxygenase-1 promotes delayed wound healing in diabetic rats. J Diabetes Res 2016: 9726503, 2016.

44. Stocker R, Yamamoto Y, McDonagh AF, Glazer AN and Ames BN: Bilirubin is an antioxidant of possible physiological importance. Science 235: 1043-1046, 1987.

45. Ryter SW, Alam J and Choi AM: Heme oxygenase-1/carbon monoxide: From basic science to therapeutic applications. Physio Rev 86: 583-650, 2006.

46. Ryter SW, Otterbein LE, Morse D and Choi AM: Heme oxygenase/carbon monoxide signaling pathways: Regulation and functional significance. Mol Cell Biochem 234-235: 249-263, 2002.

47. Wang XM, Kim HP, Nakahira K, Ryter SW and Choi AM: The heme oxygenase-1/carbon monoxide pathway suppresses TLR4 signaling by regulating the interaction of TLR4 with caveolin-1. J Immunol 182: 3809-3818, 2009.

48. Chhikara M, Wang S, Kern SJ, Ferreyra GA, Barb JJ, Munson PJ and Danner RL: Carbon monoxide blocks lipopolysaccharide-induced gene expression by interfering with proximal TLR4 to NF-kappaB signal transduction in human monocytes. PLoS One 4: e8139, 2009

49. Nakao S, Ogata Y, Shimizu-Sasaki E, Yamazaki M, Furuyama S and Sugiya H: Activation of NFkappaB is necessary for IL-1beta-induced cyclooxygenase-2 (COX-2) expression in human gingival fibroblasts. Mol Cell Biochem 209: 113-118, 2000.
50. Morse D, Pischke SE, Zhou Z, Davis RJ, Flavell RA, Loop T, Otterbein SL, Otterbein LE and Choi AM: Suppression of inflammatory cytokine production by carbon monoxide involves the JNK pathway and AP-1. J Biol Chem 278: 36993-36998, 2003.

51. Sarady JK, Otterbein SL, Liu F, Otterbein LE and Choi AM: Carbon monoxide modulates endotoxin-induced production of granulocyte macrophage colony-stimulating factor in macrophages. Am J Respir Cell Mol Biol 27: 739-745, 2002.

52. Jang SI, Kim HJ, Kim YJ, Jeong SI and You YO: Tanshinone IIA inhibits LPS-induced NF-kappaB activation in RAW 264.7 cells: Possible involvement of the NIK-IKK, ERK1/2, p38 and JNK pathways. Eur J Pharmacol 542: 1-7, 2006.

53. Chiu WT, Lin YL, Chou CW and Chen RM: Propofol inhibits lipoteichoic acid-induced iNOS gene expression in macrophages possibly through downregulation of toll-like receptor 2-mediated activation of Raf-MEK1/2-ERK1/2-IKK-NFkappaB. Chem Biol Interact 181: 430-439, 2009.

54. Jawan B, Kao YH, Goto S, Pan MC, Lin YC, Hsu LW, Nakano T, Lai CY, Sun CK, Cheng YF, et al: Propofol pretreatment attenuates LPS-induced granulocyte-macrophage colony-stimulating factor production in cultured hepatocytes by suppressing MAPK/ERK activity and NF-kappaB translocation. Toxicol Appl Pharmacol 229: 362-373, 2008.

55. Chen WC, Tseng CK, Chen YH, Lin CK, Hsu SH, Wang SN and Lee JC: HCV NS5A Up-regulates COX-2 expression via IL-8-mediated activation of the ERK/JNK MAPK pathway. PLoS One 10: e0133264, 2015.

56. Gu W, Song L,Li XM, Wang D, Guo XJ and Xu WG: Mesenchymal stem cells alleviate airway inflammation and emphysema in COPD through down-regulation of cyclooxygenase-2 via p38 and ERK MAPK pathways. Sci Rep 5: 8733, 2015. 